\title{
Clinical findings, course, and progress of Bietti's corneal degeneration in the Dahlak Islands
}

\author{
F. C. RODGER \\ Princess Margaret Hospital, Swindon, Wiltshire
}

Bartolucci (1933) and Zanettin (1937) reported the presence of an unusual corneal disease in Italian Somaliland and the Dahlak Islands respectively.

Falcone (1954) published an excellent detailed account based on a large sample collected over 15 years in Mogadiscio. Coinciding with his observations, Guerra in Asmara had recorded similar findings; he communicated them to Bietti in Rome, who visited Asmara and Massawa and, linking the Eritrean cases with those of de Gaspare in Saudi Arabia, carried out an intensive study of the condition (Bietti, Guerra, and de Gaspare, I955).

The lesion has since been called "Bietti's corneal dystrophy" by Gandolfi (1962) in Libya, by Etzine and Kaufmann (1964) in the Southern Transvaal, by Frétillère, Védy, and Chovet (1967) in French Somaliland, and by Freedman (1972) in South West Africa.

Freedman (1965) described a somewhat similar, if less severe, condition, named by him "Labrador keratopathy", which will be discussed later, and Wyatt (197I) reported identical cases in the North-West Territories of Canada.

In 197I, the Scientific Exploration Society invited the writer to lead a small British expedition to the Dahlak Islands to study this disease in depth in village communities (Rodger, 1972). The expedition was mounted at the request of the Ethiopian Government.

\section{Screening procedure and rates of blindness}

The Dahlak Islands have a total population of 2,620. Four categories were examined in five out of six inhabited islands: the blind, the partially-sighted, those with painful or irritable eyes, and a few others with relatively healthy eyes. We examined 228 such patients out of a population group of $\mathrm{I}, 880$ ( $7 \mathrm{I}$ per cent. of the whole). It is likely that the attendance rate of those with affected eyes was high. As it is a Muslim community, however, women did not attend as frequently as men. Thus we believe that the figures for the prevalence rates, even although derived from a method of screening well suited to a study of blinding disease, are on the low side; that is, our figures are minimal prevalence rates, particularly in the case of women.

In addition to the island villages, $4^{8}$ male salt workers - three with impaired vision out of 29 per cent. exhibiting Bietti's corneal degeneration-and Ioo naval officers, ratings, and their wives-none with impaired vision and none having corneal degeneration-were examined in Massawa. Table I gives the Dahlak results, the mean prevalence rate of blindness on the islands working out at $5 \cdot 9$ per cent., taking a standard of $6 / 60$ or worse in both eyes. All sight-testing was carried out using the Landolt-G, which excludes guessing. 
Table I Prevalence rates of blindness in survey of Dahlak Islands

\begin{tabular}{|c|c|c|c|c|c|}
\hline \multirow{2}{*}{ Village } & \multirow{2}{*}{ Population } & \multicolumn{2}{|c|}{ Persons examined } & \multirow{2}{*}{$\begin{array}{l}\text { Visual acuity } 6 / 60 \\
\text { or worse in both } \\
\text { eyes (both sexes) }\end{array}$} & \multirow{2}{*}{$\begin{array}{l}\text { Prevalence rates } \\
\text { of blindness } \\
\text { from all causes } \\
\text { (per cent.) }\end{array}$} \\
\hline & & Males & Females & & \\
\hline Gembili-Melill & 380 & $3^{2}$ & 7 & I6 & $4 \cdot 2$ \\
\hline Dubishat & 240 & $3^{\mathbf{I}}$ & 7 & 18 & $7 \cdot 4$ \\
\hline Salait & 170 & 35 & 5 & 16 & $9 \cdot 4$ \\
\hline Nora & 80 & 4 & $\mathrm{I}$ & 3 & $3 \cdot 7$ \\
\hline Nocra & 160 & 10 & I & 2 & $I \cdot I$ \\
\hline Dohul & 700 & 30 & 37 & 47 & $6 \cdot 7$ \\
\hline Dissei & 150 & 23 & 5 & 9 & $6 \cdot 0$ \\
\hline Total & I,880 & 165 & 63 & III & (Mean) 5.9 \\
\hline
\end{tabular}

In Table II the proportion of each blinding disease to total blindness is given, the proportion of cataracts ( 3 I per cent.) almost exactly representing that previously claimed to be standard in tropical countries (Rodger, 1970). The proportion of those blinded by Bietti's corneal degeneration to the total blind was high $\left(57^{\circ} \circ\right.$ per cent.). The extremely low proportions of blindness from trachoma, measles, smallpox, and keratomalacia was remarkable for this region, as there is a great deal of blindness from all four diseases on the mainland. Only two cases of Bitot's spots were seen, one (mucoid) in an island chief and the other (pearly) in an adult salt worker.

Table II Proportions of blinding diseases among Dahlak Islanders

\begin{tabular}{ll}
\hline Diagnosis & Per cent. \\
Bietti's corneal degeneration & 57 \\
Cataract & 31 \\
Unknown origin & 10 \\
Other & 100 \\
\hline Total & \\
\hline
\end{tabular}

Table III Percentage corneal degeneration in all men and women examined, blind and non-blind

\begin{tabular}{|c|c|c|}
\hline \multirow[b]{2}{*}{ Village } & \multicolumn{2}{|l|}{ Sex } \\
\hline & Male & Female \\
\hline Gembili & $4^{I}$ & 20 \\
\hline Melill & 40 & $5^{\circ}$ \\
\hline Dubishat & 53 & 71 \\
\hline Salait & 54 & $4^{\circ}$ \\
\hline Dohul & 66 & 73 \\
\hline Dissei & 39 & \\
\hline Salt pans & 27 & none examined \\
\hline Means (per cent.) & $45 \cdot 7$ & $4^{2} \cdot 0$ \\
\hline
\end{tabular}

A mean prevalence rate of blindness of 5.9 per cent. $-6 \cdot 7$ per cent. if we exclude Nora and Nocra where the attendance rates were probably low-is very high. A prevalence rate of blindness of over 5 per cent. from all causes in a community can be matched, or bettered, only in hyperendemic areas of trachoma or onchocerciasis. The very high prevalence of Bietti's corneal degeneration $-45 \cdot 7$ per cent. (99) of the males examined, whether blind or not, and $42 \cdot 0$ per cent. (26) of the females-is underlined by the data given in Table III. Table IV shows that the total number of cases of this unusual disease reported throughout the tropics to date is 963 , including those reported here. 
Table IV Total number of cases of Bietti's corneal degeneration reported in tropical climates

\begin{tabular}{|c|c|c|c|}
\hline Author & Date & No. of Cases & Region \\
\hline Bartolucci & 1933 & Not stated & Italian Somalia \\
\hline Zanettin & 1937 & 76 & Dahlak Islands \\
\hline Falcone & I 954 & $34^{\circ}$ & Mogadiscio in Italian Somalia \\
\hline $\begin{array}{l}\text { Bietti, Guerra, and } \\
\text { de Gaspare }\end{array}$ & I 955 & 69 & $\begin{array}{l}\text { Asmara and Massawa in Eritrea } \\
\text { and Hofuf in Saudi Arabia; } \\
\text { a dozen from Persian Gulf }\end{array}$ \\
\hline $\begin{array}{l}\text { Nataf, Reynon, } \\
\text { and Uveling }\end{array}$ & I 957 & $(\mathrm{I})^{*}$ & Tunisia \\
\hline Gandolfi & 1962 & 6 & Libya \\
\hline Etzine and Kaufmann & 1964 & 3 & Southern Transvaal \\
\hline $\begin{array}{l}\text { Frétillère, Védy, and } \\
\text { Chovet }\end{array}$ & 1967 & 144 & French Somalia \\
\hline Freedman & I 973 & 87 & South-West African Territory \\
\hline Rodger & 1971 & 125 & $\begin{array}{l}\text { Dahlak Islands and Massawa in } \\
\text { Eritrea }\end{array}$ \\
\hline Total & & 963 & \\
\hline
\end{tabular}

*The published photograph in no respect represents Bietti's corneal dystrophy, and I have discounted it (author).

\section{Clinical findings}

\section{Classic symptomatology}

Any attempt at classification of the clinical appearances of this disease would be an artificial one, as they are much too variable. Nevertheless, the subjects examined in the expedition, ranging in age from toddlers to old men and women, not being self-selected hospital cases, enable the writer to describe this condition in a way not previously possible, for its general clinical course could be compiled with some accuracy.

The earliest change observed occurred in the interpalpebral fissure (Fig. I). Presumably as a result of glare, the eyelids are partially closed, swollen, and encrusted with salt, especially the lower lid. With the ocular biomicroscope, in the zone of specular reflection at the anterior face of the corneal stroma, Bowman's zone was found no longer relatively translucent, as normally, but mottled, grey, occasionally with small or large clear (darker) areas, rounded or polyhedral in shape, as in the classic band-shaped keratopathy. By

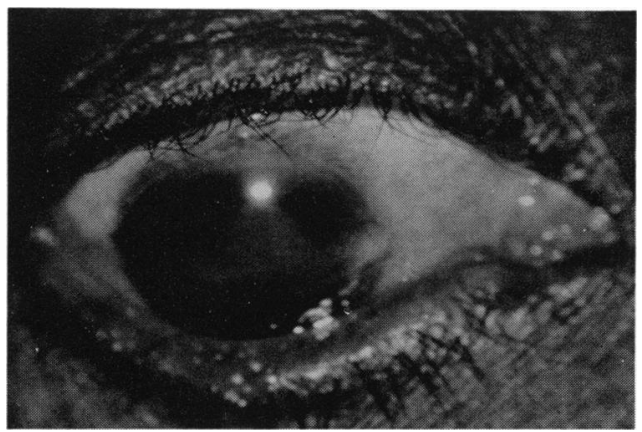

FIG. I The earliest change cannot easily be photographed but the distribution here, although more advanced and in consequence dense, conforms to the classic area affected in the early stages 
indirect illumination, the altered texture of the reflecting surface afforded by this slightly denser anterior stroma revealed the normal pattern of the overlying epithelial layers very easily; for convenience, this significant early change was described as a "veil". In optical section, the loss of transparency in Bowman's zone appeared as a thin interrupted grey line along its anterior edge. There was no staining of the corneal surface nor any sensory loss early on, only this slight alteration in the anterior face of the stroma.

When the stromal changes became (locally) more severe, the optical section showed an increased condensation and a whiter surface. Minute globules (syn. cysts or nodules) formed in front of this opacity where the epithelium separated from the underlying Bowman's membrane (Figs 2 and 3). These small globules, at first with clear contents (cysts), ultimately with light brown-coloured almost solid centres (nodules), were most commonly located at the temporal side of the veil; they might later cover the entire "veil" or the periphery, but not necessarily.

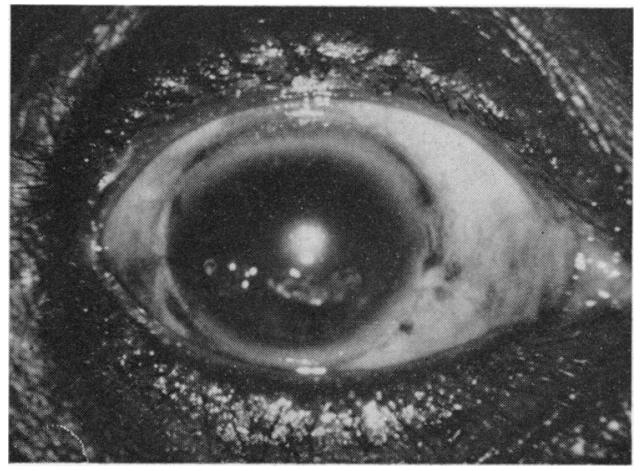

FIG. 2 Cystic changes over the entire length of the interpalpebral "veil"

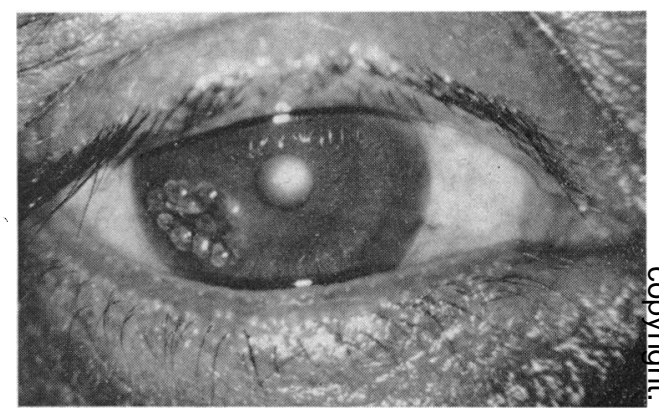

FIG. 3 Cysts with light-brown cores (semi-nodular) on the temporal side of stromal degeneration. Note also the swollen lids in a subject who was not suffering from trachoma

Whenever the corneal stroma revealed a white band in optical section, with or without cysts or nodules, there was always some loss of sensation. This loss might be as great as 5 g. per sq. mm. of pressure when using a "Cochet" aesthesiometer nylon monofilament (which is $0.12 \mathrm{~mm}$. in diameter) as compared with the unaffected parts of the cornea. By now, probably because the stromal change had acted like a tinted filter, the eyelids were held more widely open and the exposed area was larger; in more advanced cases, the shape became elliptical in consequence, corresponding to the shape of the greater exposed area of the cornea (Fig. 4). The nodules increased in number with age, as did the density and depth of involvement of the anterior stroma. The central part grew slowly thinner, as the whitening stroma contracted, involving Descemet's zone as well; when this happened the central nodules started to slough. Such an area was totally anaesthetic, so that it was not uncommon to find salt, or sand, or, in some patients, pieces of shell, sticking to the depressed white central zone, surrounded by its peripheral cysts (Fig. 5).

Measurement of the tear flow by Schirmer's test revealed no reduction at any stage, but staining of surface erosions especially after cyst or nodule formation was common. It was also sometimes seen over the associated "veil" early on. It did not, in fact, conform to any particular circumstances or pattern: sometimes the tip of the globules stained, sometimes the furrows, sometimes the surface of the veil, no matter whether the stromal 
change was grey or white in that region. Hudson-Stahli lines were also sometimes present in the area of the veil as well as erosions, so the cause of the staining may have been traumatic. Twice, epithelial filaments were noted on the affected unhealthy epithelium.

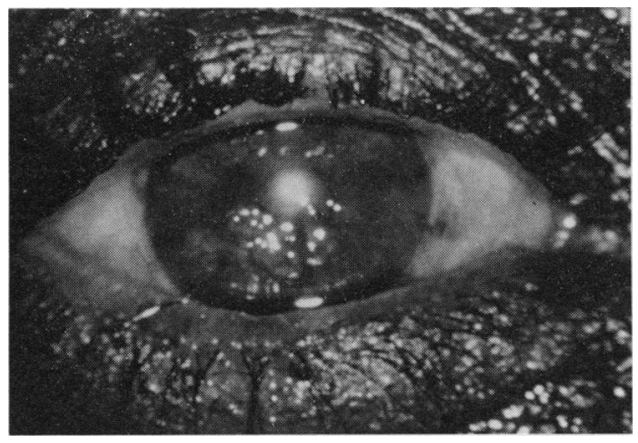

FIG. 4 Advanced stage revealing bi-convex shape, the lower outer half only being nodular

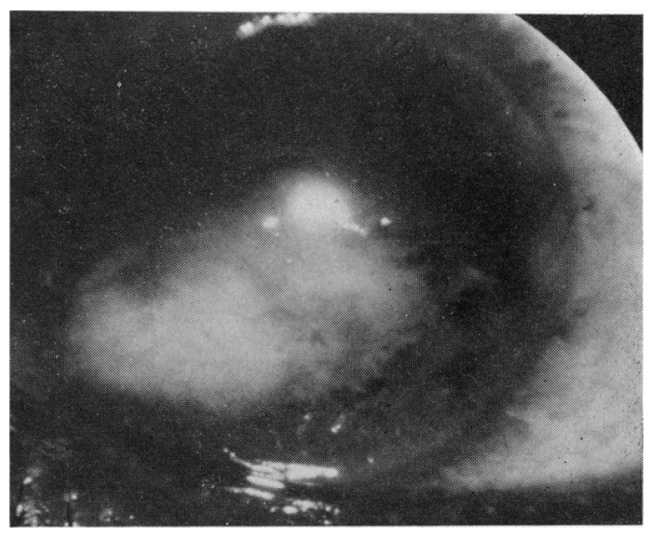

FIG. 5 Classic corneal leucoma of the lesion with nodular periphery above and pigmented margin below, the end-picture of Bietti's corneal degeneration

\section{Associated symptomatology}

If the pathogenesis, as all previous workers have postulated, depends upon exposure to abnormal climatic conditions, then one might assume there would be a close association with pterygia. Freedman (1965) found no such association in the case of the bandshaped keratopathy seen in Labrador. In the Dahlaks, pterygia were twice as common in those exhibiting this lesion. Yet overall, pterygia were not common, the incidence being under 2 per cent., so perhaps nothing should be concluded from this finding.

Arcus lipidalis was uncommon in the younger age groups, but very common in those over 50 years old. Arcuses without a lucid interval-a lesion composed of an inflammatory cell infiltration at the periphery, described several years ago and named arcus tropicalis (Rodger, 1958) - were very common in most age groups. This clinical feature may have concealed some lucid intervals in the band-shaped lesions under discussion but not as a rule. Traumatic scarring, either from injury or native methods of treatment, was far less frequent than on the west coast of Africa. Signs of malnutrition were also rare.

Although genetic inheritance patterns for Bietti's corneal degeneration were never far from our thoughts, no evidence pointing that way could be obtained. The islanders are of mixed race with Arab, Danakil, Tigrean, Afar, and African blood in their veins. Up to some 25 years ago women from Saudi Arabia and Yemen were brought over by dhow as wives; this source has now been stopped but wives can be and are obtained from the Eritrean mainland. No familial eye disease was seen and cousin marriages, we were assured, are disliked as in Europe.

One clinical clue was obtained which might prove to be of the highest significance; a women in her forties presented with photo-ophthalmia, that is, severe pain, epiphora, photophobia, and blepharospasm. On staining with bengal rose the corneae were stippled and epithelial elevations were regularly dispersed over each surface. There was no rise in ocular tension and she did not suffer from trachoma. This resembles the appearance of industrial photo-ophthalmia. 
Finally, the most severe clinical manifestations of Bietti's corneal degeneration generally occurred in the elderly in the proportion of two men to one woman. Where this disease was not present in the elderly, there always seemed to be an obvious reason: either the subject was a goatherd, or had not remained a fisherman for very long, or he was a builder of dhows who, like the head men, had more money and invariably wore sunglasses. The youngest males we discovered with Bietti's corneal degeneration were two boys aged 12 and I 4 , and the youngest woman out of the 26 affected was 22 years of age. The association of cataracts, often hypermature and white, made it easier to pick out even the finest veil with the naked eye in the elderly or middle-aged; it was not so easy in the young. Fig. 6 shows the relation of (arbitrary) degrees of severity of the lesion to age, supporting the assertion that the worst cases were found in the old. Fig. 7 indicates that the prevalence of the disease in both men and women rises steadily with age from the twenties in men and the thirties in women. A study of these two graphs shows that the development of blindness, although not inevitable, is the likely ending, and that the course of the disease is lengthy, with blindness increasingly common after the fiftieth year.

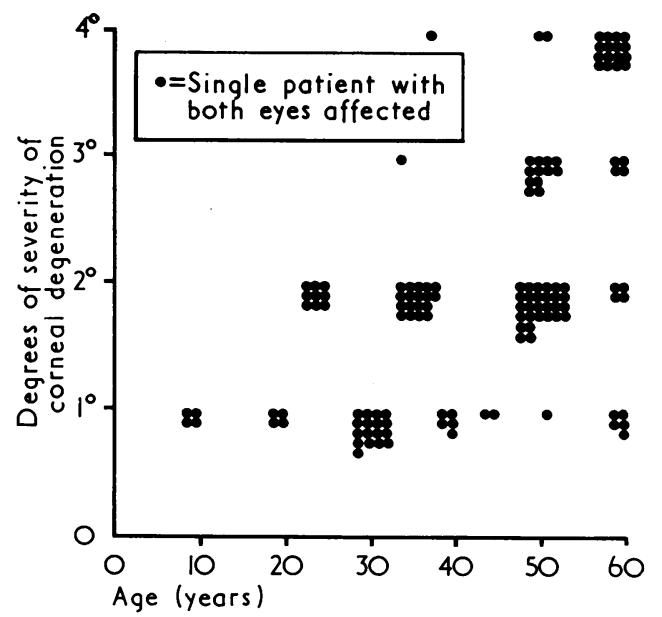

FIG. 6 Increased severity of the lesion with age

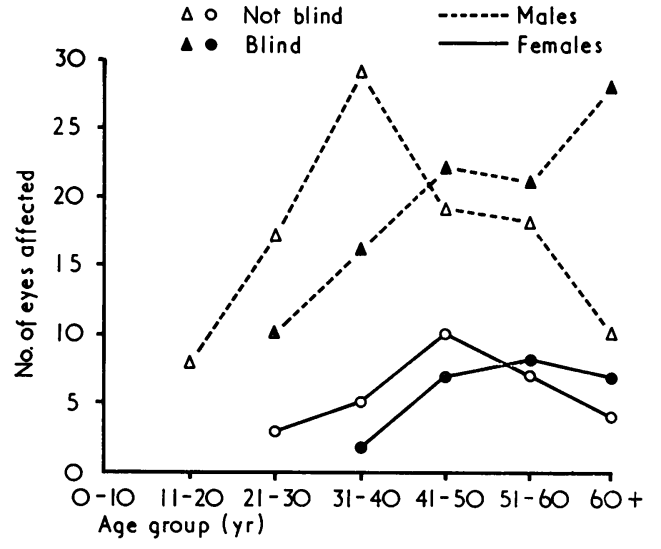

FIG. 7 Age at onset and prevalence of Bietti's corneal degeneration in males and females, parallel with blindness in relation to age

\section{Discussion}

It is difficult to find a good term to describe the interesting ocular disease seen in the Dahlak islands. If one has to be exact the clinical findings suggest that it is not always nodular, nor is it a dystrophy, although it is usually more or less band-shaped. A nodule presupposes a solid content which, as we have seen, only occurs later on and then partially; originally the change affecting the epithelium is cystic. A dystrophy is now generally considered to be a cytological alteration, the result neither of inflammation, nor of a systemic disturbance, nor of ageing: in short, a dystrophy is usually developmental and frequently hereditary. If, as is possible, the causative agent in Bietti's corneal lesion is actinic radiation, then properly the change is degenerative and follows cumulative chemical sunburning. If, as others have said, it is due to various hostile elements in the environment, the resultant stromal change must similarly be categorized as degenerative. As a result of structural alteration in the stroma, whatever the cause, a disorder of the overlying epithelium might reasonably be expected to follow. In consequence the terms 
"dystrophy" and "keratopathy" in connection with this disease are probably not good ones. As an exact definition of the complete lesion would depend upon the exact pathogenesis being proven, we have preferred to call it here "Bietti's corneal degeneration".

Freedman (1965) described the condition affecting the eyes of arctic fishermen as "a non-familial, usually symmetrical, bilateral corneal degeneration, probably caused by exposure to climatic extremes". This paper is an important work, although preceded in time, as we have seen in the introduction, by various reports from the Red Sea area. The parallels between climatic conditions in Africa and Canada and the probable aetiology, at first sight somewhat obscure, are listed as follows by Freedman: "low relative humidity in winter and minute ice or dust particles carried by strong seasonal winds". A paper by Rodger, Guthill, Lenham, and Fydelor (1974) indicates that it is most probably only the degree of solar radiation which matters, especially short wave lengths (300-310 $\mathrm{nm}$.) reflected at eye level from white coral sand or salt on the one hand, and from snow and ice on the other, in areas with a clear atmosphere and little shade. However, there are, as has been touched on above, many differences between the two ocular symptomatologies in the tropics and the arctic, which should be discussed briefly.

The most obvious dissimilarity is that the Dahlak lesion was quite frequently assymmetrical, yet symmetry was a feature always stressed in the Labrador cases. The fenestrations or holes or bites out of the edge of the band shape, and the lucid intervals, classically present in all band-shaped keratopathies and apparently always present in Labrador keratopathy, were also more often absent than present in the Dahlak eyes. As the lesion advanced, these signs became even less frequent. The shape of the affected part of the cornea, picked up early as a "veil", varied considerably in Dahlak eyes, nor did the lesion build itself up in depth in stages as described by Freedman, although this was observed in the odd case.

In the majority the entire exposed area of one or other cornea (less rarely both) was affected in a thin transverse band from one side of the limbus to the other, but affected to a varying degree in depth. In early cases, the shape often consisted of a rectangular strip, or parts of a strip, about $2 \mathrm{~mm}$. in its vertical height; rarely, it was higher at each side, that is to say its limiting margins were concave lines: it was bi-concave. As the condition advanced, the limiting margins always became convex, that is the central vertical diameter became the widest; in short, as described above, the shape of the lesion could now be decribed as bi-convex. This was apparently never seen by Freedman, whose drawings indicate a bi-concave shape only.

The globular swellings on the surface of the cornea in Dahlak eyes were occasionally very large, with deep furrows; even then the light-brown contents, described so well as oil droplets by Bietti, lay centrally within a clear watery material. In short, the initial cystic appearance never completely altered to a totally solid nodule. The appearance in the Labrador cases was described on the other hand as "glistening, yellowish-brown subepithelial nodules", which suggests they were coloured nodules solid throughout. Moreover, in only one case out of 69 patients observed by Freedman did the nodules form in a number sufficiently appreciable to be described as "an excrescence", whereas in the Dahlak eyes this was commonplace. The cysts looked like bunches of mini-grapes. Despite these major differences, we are probably dealing with the same condition, the variations depending upon the differing intensities of the causative agencies and the duration of exposure. It would be an over-simplification and not altogether accurate to say that Labrador keratopathy describes the early stages of Bietti's corneal degeneration (Rodger, 1972), but it is a helpful concept. 
There is a great deal of indirect evidence on the effect of ultraviolet rays (at $307.5 \mathrm{~nm}$.) on the skin (Urbach, I969), which supports the claim that it is cumulative damage from these rays to the corneal stroma which gives rise to Bietti's degenerative lesion. This topic will be taken up, however, in further publications which are pending, from data and material obtained during this same expedition. At the moment, the pathogenesis is conjectural.

I am very grateful to Mrs. Alec Gale and her family and to Jack Ainslie (the Treasurer) for organizing the Alec Gale Memorial Fund, without which this survey could not have been carried out. The assistance afforded by the Scientific Exploration Society's executive members in planning was invaluable. In Ethiopia, my respectful thanks are expressed to His Excellency Commodore Alexander Iskindir Desta, Commanding Officer of the Imperial Ethiopian Navy, and to the Chief Operations Officer at Massawa, Captain Peter Stewart RN (Rtd), for support in transporting the expedition and its inflatable craft by gunboat and also in maintaining lines of communication and carrying water and stores. Finally, to Mahomed Seraj Khalil, Paramount Sheikh of the Dahlak islands, who worked so hard and effectively to help us move from island to island, my team and I are everlastingly grateful.

\section{References}

Bartolucci, F. (1933) Arch. ital. Sci. med. colon., 14, 430

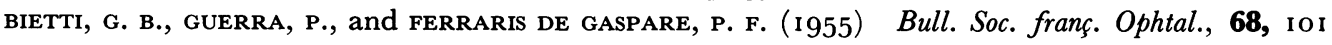
etzine, s., and kaufmann, J. c. E. (1964) Amer. F. Ophthal., 57, 760

FAlCONE, G. (1954) Riv. ital. Tracoma, 6, 3

FREEDMAN, A. (1965) Arch. Ophthal. (Chicago), 74, 198

FREEDMAN, J. (1972) Brit. med. F., I, 379 (1973) Brit. F. Opthal., 57, 688

FRÉTILLÈre, Y., VÉDY, J., and CHOVET, M. (1967) Méd. trop., 27, 293

GANDOLfi, A. (1962) Boll. Oculist., 4I, I 29

NATAf, R., Reynon, B., and UVeling, N. (1957) Ann. Oculist. (Paris), 190, $3^{\text {I } 6}$

RODGER, F. C. (1958) Amer. F. Ophthal., 45, 343

- (1970) "The Simulium Control Scheme at Abuja". W.H.O. unpublished report, AFR (ONCH) I 7, Appendix I

(1971) Brit. med. F., 4, 8I I

—, CUTHILl, J. A., LENHAM, A. P., and FYdeloR, P. M. (1974) "The probable effect of UVR

in the production of corneal degenerative changes under certain physiographic conditions".

Awaiting publication

URBACH, F. (I969) “The Biologic Effects of Ultra-Violet Radiation", pp. 635-65o. Pergamon

Press, Oxford

WYATT H. (197I) "Incidence of Labrador Keratopathy in North West Territory of Canada".

Trans. II Conf. Int. Soc. Geograph. Ophthal. (at Jerusalem Seminar on Prevention of Blindness) zanettin, G. (1937) Arch. ital. Sci. med. colon., 18, 387 